Journal of Engineering and Applied Sciences 15 (4): 960-964, 2020

ISSN: $1816-949 \mathrm{X}$

(C) Medwell Journals, 2020

\title{
Follow-up to the Customs and Traditions of the Labor of Domiciliary Childbirth in Women of the Andean Communities of: Salinas, Cuatro Esquinas, Cachisagua and Santa Fe of Guaranda (Ecuador)
}

\author{
${ }^{1}$ Silvana López Paredes, ${ }^{1}$ Víctor Hugo Núñez, ${ }^{1}$ María Olalla García, ${ }^{1}$ Mery Rocío Rea, \\ ${ }^{1}$ Maura Muñoz Naranjo and ${ }^{2}$ Favian Bayas-Morejón \\ ${ }^{1}$ Facultad de Ciencias de la Salud y del Ser Humano, Carrera de Enfermería, \\ 020150 Guaranda, Ecuador \\ ${ }^{2}$ Carrera de Agroindustria, Departamento de Investigación, Centro de Investigación y Desarrollo \\ Biotecnológico, 020150 Guaranda, Ecuador
}

\begin{abstract}
This wording is a follow-up to home birth that takes place in the communities of Salinas, Cuatro Esquinas, Cachisagua, Santa Fe, Canton Guaranda, province of Bolivar and that in our country is a millenary practice making uancestral ritual which has allowed us to know different techniques that are performed at the time of home birth, its actors and the reasons why some women prefer home delivery but not the hospital. Community midwives play a fundamental role in this act, since, they are the ones who in accordance with their knowledge and traditions, welcome the newborn, an activity that they carry out for generations (offspring and knowledge inheritance) framed their participation and the relationship that they have a hospital health center, showing, therefore, the relationship with the nursing staff in the community that seeks the satisfaction of the needs as well as sharing and respecting their beliefs, values, customs, traditions, culture and language in a process integrator being this the home birth, likewise by means of this writing it was determined that even at present it is still maintaining the traditions including the ancestral medicine in some communities where the midwives play a very important role at the time of doing this work.
\end{abstract}

Key words: Domiciliary childbirth, andean communities, tradition, Ecuador, participation, customs

\section{INTRODUCTION}

This research was carried out in the Andean communities of Salinas, Cuatro Esquinas, Cachisagua and Santa $\mathrm{Fe}$ in the Canton of Guaranda, province of Bolivar (Ecuador), considering 16 parturients of Salinas, 12 parturients of Cuatro Esquinas, 7 parturients de Cachisagua and 10 parturients of Santa Fe, counting with a total of 45 parturients who were interviewed with a general mean of age of 27 years.

Interview with the midwife of the Salinas community: The midwife ladies have said that home birth is a tradition that has been taking place for several years, husbands were those who attended the birth but with the passing of time has been delegated to women called midwives, this knowledge has acquired from demonstrations of their grandmothers, mothers or family and the opportunities of having helped in different births. This delivery is carried out many times by alternative because of various circumstances such as the distance from home to the health center or an hospital unit and other times optional, since, the mother can choose where to give birth to her child, women at the time of delivery they feel more secure, confident, therefore, they are in a familiar environment and intimate, it is estimated that the treatment is more humane, even midwives have received recognition from health institutions. In general, midwives have cared for many women in their family environment becoming an important figure in the community who will have the task of spreading his knowledge to new generations.

\section{MATERIALS AND METHODS}

Procedure of home delivery: Home delivery is performed at home, the midwife helps the mother from five to 8 months to the creature is placed inside the belly for which tea infusions with pumin (Salvia squalens), rue (Ruta graveolens), liquor, lemon and sugar. New mothers decide to light at home on the recommendation of their mother and mother-in-law, "given that the vagina no one but the husband and the midwife has to see".

Corresponding Author: Favian Bayas-Morejón, Carrera de Agroindustria, Departamento de Investigación, Centro de Investigación y Desarrollo Biotecnológico, 020150 Guaranda, Ecuador 
At the beginning of the labor, the relatives are with the parturient, all the time the stove is on to give a warm atmosphere, prayers to scare away the evil spirits and allow the good ones to abound and favor in this process, the infusions of water of cinnamon with drink do not lack on the embers, the midwife takes the pulse and shows that when the pulse is in the wrist is not yet in time but when this is in the arm it is time of delivery that coincides with the contractions on the other hand, the materials that are going to be used are sterilized in a bath-maid (scissors, guillet, threads), the mother is made to lie down with the same clothes that are in that moment, they only cover her at the height of the belly with a clean blanket, the midwife uses a gown and sometimes surgical gloves provided by the health center or as she states: "Hands freshly washed" in the first pains of the mother midwife prepares remedy waters with melloco (Ullucus tuberosus), pumpkin seeds (pumpkin Auyama) and flaxseed (Linum usitatissimum) and anise water with a drink glass which will help in childbirth at that time a massage is performed in the belly to identify in which position is the head of the baby what is called manteo is done which consists of placing a blanket on the back pulling a person on the right side (usually husband) and the other on the left to accommodate the baby, then a pill is given which is called a "strength pill" with a cup of anise (Pimpinella anisum L.) with a little bit of drink and sugar is left to boil and the mother is given to drink in puffs, so that, it has a better effect with the husband's help is made to lie down straight in the place that the mother prefers, be it the bed or the floor, there are mothers who prefer to shine on their knees or stand up when the pains are stronger the mother's "rump" should be supported and make her walk to the point that the child is already close to descending is when chicken butter is heated, same that is prepared days before, melting all the fat of the field chicken also used the cocoa butter; you have to melt it in a cup or another container, then you rub it in the lower part of the belly by making gentle movements or light shaking, either standing or lying down, the fountain water is lowered and the baby keeps descending with the previously mentioned waters ingested in murmurs, there is heat and profuse sweating in the mother which stimulates the acceleration of the constant bids waiting only the total descent of the baby, the midwife receives the child, then the umbilical cord is cut with the scissors if a man is cut four fingers (approximately $4 \mathrm{~cm}$ ) when a woman three fingers (approximately $3 \mathrm{~cm}$ ) after delivery the midwife cures the bad air (disease caused by the penetration of a noxious vapor into the body ) with field hen, rubbing gently on the lower abdomen, then the chicken is cooked and the fat gives the child two drops, this in order to prevent him from getting sick in the future. The mother is given to eat brown sugar, so that, the "Madre" (placenta) comes out. In the stove "Fogon" a series of medicinal plants is boiled to wash the blood given that the vagina is inflamed.

The child is covered "manteado" or wrapped "maito" (quichua term "general wrap of the baby) in blankets and blankets by the midwife without forgetting the ombliguero (covers navel), cap. While the accompanying women offer blessings to the newborn and simulate each of them "sew the baby's mouth", so that, it is not a gossip "metecuentos".

After a few minutes the woman is put to bed, covered with blankets and previously placed a band on the upper abdomen to prevent the "mother" (Term with which they refer to the uterus) does not rise to the heart, leaving the breasts free to facilitate breast feeding of the child which is manifested that also helps the descent of the "bad blood", the mother continues with hot drinks for milk production, her head is also tied and a cap is placed woolen. Finally, the parturient is recommended to lie down, so that, the mother (uterus) does not get off, also, must follow a diet based on cauca (cast made from the powder obtained by grinding corn), broth chicken field, castings (creams from: cereal flours or pseudo-cereals) and avoid eating rice for 42 days or at least a month, oats are not recommended or banana, since, these cause cramps to the mother and her child.

After 4 or 5 days, the midwife returns to visit the mother to bathe her with water previously boiled for $10 \mathrm{~min}$, the water contains medicinal plants such as: Santa Maria (Tanacetum parthenium), rue (Ruta graveolens), marco (Ambrosia peruviana $W$ ), chamomile (Chamaemelum nobile) but preventing the head from getting wet in addition the encamping procedure is performed which consists of the mother being made to lie down, wrapped in blankets and savannahs with force (with the help of relatives) on one side and another, so that, only the breasts are discovered for breastfeeding, this practice is done with the purpose that the bones of the hip join and return to their place. Also, an infusion of matico water (Buddleja globosa) and two leaves of mallow (Malva sylvestris) with swallow and two drops of cologne are prepared for the mother to harden the body and recover strength.

The payment of the research of the midwife varies according to the product that brings to the world if it is male it charges thirty dollars, since, "cut of the pupo (navel) is fundamental" on the other hand in the women it charges between 10 or $20 \$$, since, the childbirth is not very complicated (Table 1-4). 
Table 1: Number of pregnant women in the community of Salinas

\begin{tabular}{llc}
\hline Mothers (Pregnant) & Age & Gestation weeks \\
\hline 1 & 26 & 39 \\
2 & 28 & 40 \\
3 & 24 & 36 \\
4 & 32 & 35 \\
5 & 29 & 32 \\
6 & 37 & 35 \\
7 & 27 & 37 \\
8 & 36 & 40 \\
9 & 28 & 40 \\
10 & 36 & 40 \\
11 & 26 & 39 \\
12 & 37 & 40 \\
13 & 29 & 39 \\
14 & 35 & 37 \\
15 & 18 & 38 \\
16 & 39 & 40 \\
\hline
\end{tabular}

Table 2: Number of pregnant women in the community of Cachisagua

\begin{tabular}{llc}
\hline Mothers (Pregnant) & Age & Gestation weeks \\
\hline 1 & 28 & 27 \\
2 & 24 & 34 \\
3 & 23 & 31 \\
4 & 26 & 30 \\
5 & 15 & 25 \\
6 & 21 & 36 \\
7 & 22 & 36 \\
\hline
\end{tabular}

Table 3: Number of pregnant women in the community of Santa Fe

\begin{tabular}{lcc}
\hline Mothers (Pregnant) & Age & Gestation weeks \\
\hline 1 & 29 & 24 \\
2 & 19 & 21 \\
3 & 32 & 12 \\
4 & 26 & 31 \\
5 & 37 & 16 \\
6 & 27 & 34 \\
7 & 36 & 25 \\
8 & 28 & 25 \\
9 & 36 & 25 \\
10 & 38 & 27 \\
\hline
\end{tabular}

Table 4: Number of pregnant women in the community of Cuatro Esquinas

\begin{tabular}{llc}
\hline Mothers (Pregnant) & Age & Gestation weeks \\
\hline 1 & 29 & 24 \\
2 & 31 & 27 \\
3 & 19 & 30 \\
4 & 36 & 29 \\
5 & 25 & 32 \\
6 & 29 & 24 \\
7 & 24 & 27 \\
8 & 28 & 36 \\
9 & 30 & 33 \\
10 & 17 & 22 \\
11 & 36 & 27 \\
12 & 22 & 31 \\
\hline
\end{tabular}

\section{RESULTS AND DISCUSSION}

Population of pregnant women in the communities: In this follow-up an interview was conducted with mothers who have had a home delivery in which they tell us that they prefer to give birth or give birth at home due to different circumstances including distance from home to the health center, lack of transportation at night, not having money for the purchase of medication and supplies requested in the prescriptions, bad information and for the treatment they have received and that at times have been very bad because at the time of delivery in the hospital never give them medicinal waters that help to sweat and provoke the pain "pujos" and that they are accustomed to drink at the time of admission to the hospital they remove their clothes and immediately they shower, the medical acts are not explained nor they ask for your authorization, taking you away from your companions and your partner; when the moment of delivery arrives, it is performed in an operating room, a completely unknown environment, they make him go up on the cold stretcher and he asks him to open his legs and rudely ask him to push without asking if he wants to be in that position. That is his opinion is canceled. In counterpart we have what the Ministry of Public Health of Ecuador, through the process of standardization of the national health system and the subprocess of normatization of intercultural medicine has been implementing work of recognition, revaluation and recovery of knowledge and cultural practices of medicine ancestral, emphasizing the training to the wise of the ancestral medicine identified from the community throughout the country is so that, put into consideration the technical guide of culturally adequate birth in the year 2008 marking the beginning of the implementation of the care of normal delivery with intercultural considerations; is that until 2013, the areas of delivery care have been adequate to guarantee the free choice of childbirth (Gonzalez and Corral, 2010).

This reality is not alien to the experiences that many indigenous women live in the Peruvian jungle where as in our country, the parturient choose the native birth, since, once the birth process is initiated the midwife is called in other cases they are attended by the older women of the family or the husband to favor a successful delivery the midwife makes sure that everything is arranged horizontally which will support the woman during childbirth in addition to the support of the husband, the midwife and the person who helps in the birth, the raw egg white is ingested, so that, the delivery is faster; meanwhile a thread is boiled in water and the edge of a morona to cut the navel of the baby, if placenta retention is present, ginger is used in infusion and rubbing or also mikut (peel of the stem that is scraped, squeezed and Is taken) (Nurena, 2009; Tarqui and Barreda, 2005).

They care a lot for the parturient woman, so that, she does not get cold (air) during the delivery, since, if this happens, the birth of the fetus will be delayed, vaginal bleeding for that she is given hot herbs like matico, 
albaca, cotton. They also avoid any situation that may cause a fright during pregnancy as this will cause the woman to convulse during delivery (Medina and Mayca, 2006; Aguilar et al., 2013). These versions are related to what the parturient of the communities where the follow-up was carried out and have been disseminated in the community according to their own reality, emphasizing that with a home delivery or home birth they can have the support of her husband, family, a quiet environment and being able to give birth as they wish assisted by the midwives. Fear is another factor that exacerbates the pain and prevents the connection with the instinct and in a foreign place, full of strangers, it only increases, making a longer and more painful process; unlike what happens in your home, the woman lives her work in freedom: a place sheltered by dry firewood, freedom and comfort is respected in account of her position, she has enough space to move, she can rest with confidence, baby and eat if you wish, there is sufficient silence, shelter and darkness, no intestinal washes are done if excessive touches or vaginal cuts are not necessary (Castillo-Santana et al., 2017).

The interviewed mothers do not show risks in the home birth, since, they have never had problems or complications at the time of delivery for that reason they feel safe, they also tell us that in the hospital a cesarean is performed while in antiquity this was not common; however, the Ministry of Public Health, through the Maternal and Neonatal Care Standards and Protocols, including the culturally appropriate delivery guide and the manual of standards and indicators, seek to improve the quality of maternal and neonatal care, developed in the framework of the Plan Accelerated Reduction of Maternal and Neonatal Death (MSP., 2016).

\section{CONCLUSION}

As a result of this follow-up we have learned that a home birth with midwife ensures the intimacy of the woman who is about to give birth and that she feels more comfortable giving birth in her home with her family, the home birth is a tradition according to their culture, since, this has been done up to now but not all families agree with this as they want to keep the safety of both the mother and her child by placing them in the hands of people trained in health as they are the sub centers, hospital units because both a hospital birth guarantees the well being of both the mother and the child, since, the necessary measures are used for a correct delivery of life. The majority of circumstances for which mothers do not come to give birth in hospitals is because of the distance because they are families that live in distant communities and do not have the necessary resources to be able to attend a hospital (Arguello et al., 2018). The disaggregated data show that more than $40 \%$ of women in provinces such as Bolivar, Chimborazo, Cotopaxi and Esmeraldas and around $30 \%$ of women in the entire Amazon region, gave birth at home (MSP., 2008).

Contributions: SLP participated in the collection of information. VHN participated in the collection of information. MOG performed the interpretation of the information. MRR participated in the collection of information. MMN collaborated with the linguistic revision of the research. FBM participated in the interpretation of the results and submission of the manuscript.

\section{ACKNOWLEDGEMENTS}

To the pregnant women, midwives and relatives of the communities of Salinas, Cuatro Esquinas, Cachisagua and Santa Fe of the Guaranda (Ecuador).

\section{REFERENCES}

Aguilar, O.C., A.L.F. Romero and V.E.M. Garcia, 2013. Comparison of obstetric and perinatal results of childbirth vertical position vs childbirth supine position. Ginecologia Obstetricia Mexico, 81: 1-10.

Arguello, J., L. Sanchez, M. Tapia, M.M. Ortiz and F. Flores et al., 2018. Factors that affect cesarean delivers in the general hospital of Guaranda (Ecuador). Asian J. Pharm., 12: S636-S639.

Castillo-Santana, P.T., E.D. Vallejo-Rodriguez, K.P. Cotes-Cantillo and C.A. Castaneda-Orjuela, 2017. Indigenous maternal health in women from nasa and misak ethnicities from Cauca, Colombia: Tensions, subordination and intercultural dialogue between two medical systems. Saude Soc., 26: 61-74.

Gonzalez, G.D. and F.J. Corral, 2010. [Ministry of public health of national directorate of regulations of the sns intercultural health subprocess]. UNFPA/Ecuador Ministry of Public Health of Ecuador, Quito, Ecuador. (InSpanish) http://www.maternoinfantil.org/archivos/ smi_D277.pdf

MSP., 2008. Technical guide for care of culturally appropriate birth. Ministry of Public Health of Ecuador, Quito, Ecuador.

MSP., 2016. Delivery of caesarean delivery. Clinical Practice Guide (GPC)., Ministry of Public Health of Ecuador, Quito, Ecuador.

Medina, A.I. and J.P. Mayca, 2006. [Beliefs and customs related to pregnancy, childbirth and the puerperium in native communities Awajuny Wampis (In Spanish)]. Peruvian J. Exp. Med. Publ. Health, 23: $22-32$. 
Nurena, C.R., 2009. Incorporation of an intercultural approach in the Peruvian health care system: The vertical birth method. Rev. Panamericana Salud Publ., 26: 368-376.
Tarqui, C. and A. Barreda, 2005. Factors associated with the choice of home birth in a primary care area. Callao Peru Peruvian J. Exp. Med. Publ. Health., 22: $109-116$. 